\title{
Body composition and maximal oxygen consumption in adult soccer players in the Republic of Macedonia
}

Jasmina Pluncevikj Gligoroska*, Sanja Manchevska, Ljudmila Efremova, Lidija Todorovska, Slobodan Nikolic

Department of Physiology, Medical Faculty, University Ss Cyril and Methodius, Skopje, Republic of Macedonia

\begin{abstract}
Introduction: The purpose of this study was to investigate the relationship between active and passive body mass components and maximal aerobic consumption (VO2max) in adult male soccer players.

Methods: The study involved seven hundred (700) male soccer players, mean age $25.06 \pm 4.41$ years (range 18 to 35), divided in six age groups. Body composition was assessed according the anthropometric protocol by Matiegka, and relative muscle mass (MM\%), bone (BM\%) and fat (BF\%) and absolute muscle mass (MMkg), bone (BMkg) and fat (BFkg) components were calculated. The Bruce protocol (incremental multistage treadmill test) was used for the estimation of maximal oxygen consumption.

Results: Mean values of body mass components for total sample were as follows: muscle mass $(\mathrm{MM} \%)=52.75 \pm 2.63 \%$, bone mass $(\mathrm{BM} \%)=16.63 \pm 1.29 \%$ and body fat $(\mathrm{BF} \%)=14.12 \pm 1.54 \%$. Mean VO2max was $48.89 \pm 5.17 \mathrm{ml} / \mathrm{kg} /$ minute. Relative muscle mass (MM\%) showed similar values across age different groups (ANOVA: $F=2.174 ; p=0.06$ ) while absolute muscle mass (MMkg) showed tendency of increment with age (ANOVA: $F=2.136 ; p=0.01$ ). Body fat (BFkg and $B F \%$ ) was statistically higher in the older groups (ANOVA $F=3.737 ; p<0.01$; ANOVA $F=4.117 ; p<0.01$ ). Weak positive correlation between VO2max and muscle component $(r=0.243 ; p<0.001)$ and a weak negative correlation between $\mathrm{VO} 2 \mathrm{max}$ and body fat $(r=-0.08 ; p<0.05)$ were found.
\end{abstract}

Conclusions: Our results confirm the assumption that subjects with larger muscle mass have greater endurance and higher maximal oxygen consumption compared to subjects with larger body fat component.

Keywords: body fat; muscle mass; maximal oxygen consumption; soccer players

\footnotetext{
*Corresponding Author: Jasmina Pluncevikj Gligoroska, Department of Physiology, Medical Faculty, University Ss Cyril and Methodius, Skopje, Republic of Macedonia.

E-mail: jasnapg65@yahoo.com
}

Submitted: 5 October 2015 / Accepted: 16 December 2015 DOI: http://dx.doi.org/10.17532/jhsci.2016.268

UNIVERSITY OF SARAJEVO FACULTY OF HEALTH STUDIES

\section{INTRODUCTION}

Body composition and maximal oxygen consumption are essential indicators of good physical fitness in soccer players. Most of the studies report that well developed muscle component (mass) and low percentage of subcutaneous adipose tissue are 
predictors of good sport performance (1-3). Above average or high percentage of adipose body component, impairs sports performance because adipose tissue acts as dead weight in activities where body mass must be lifted repeatedly against gravity $(2,4)$.

Ergometry testing estimates the quality of physiological response of cardiovascular system on physical effort, and provides specific parameters of cardiovascular endurance. Along with the estimation of body composition, it is an important part of the physical exam within sport medicine. Maximal oxygen consumption (VO2max), as a final parameter of most ergometry testing, has been generally accepted as the best measure of the functional limit of the cardiovascular system and is commonly interpreted as an index of cardio-respiratory fitness (5). Maximal aerobic consumption is useful and practical predictor that helps monitoring aerobic performance changes in soccer players $(6,7)$. The relationship between body composition and aerobic power is of great interest for the coaches, strength and conditional specialists. The fact that physical stress during training sessions and competition may modulate body composition and influence aerobic capacity, suggests that there could be association between anthropometric and physiologic parameters (8-10).

Although anthropometric and ergometry testing are widely used in sports population, there is still a deficit of coherent data for soccer players in the literature. Different methodology and formulas applied for the calculation of body composition and different methods for the estimation of maximal oxygen consumption (direct or indirect, maximal or submaximal methods which employ different types of ergometers) may cause difficulties in comparison of the results of studies from different countries (nations).

During the last 30 years, in the Republic of Macedonia, regular periodical systematic sports medical exams of athletes have been performed in the Department of physiology at the Medical Faculty in Skopje, which has been the first and still the largest sports medical institution in our country. The same anthropometric and ergometry methods have been used since the foundation of our institution, with the new methods introduced recently. To date, we have published detailed anthropometric dimensions of adult male soccer players $(11,12)$. However, there is still no report regarding maximal oxygen consumption and its correlation with body components in soccer players in our country. Among many factors that influence football success, physical fitness and endurance of the players are most important ones.

The aim of this study was to quantify body mass components and maximal aerobic consumption (VO2max) in adult soccer male players and to investigate the correlation between body mass components and maximal aerobic consumption.

\section{METHODS}

\section{Study design}

We analyzed the records of soccer players playing in the first national league who were subjected to systematic sports medical examinations over a ten-year period (2003-2012). The study was approved by the Ethical committee of Medical Faculty in Skopje.

\section{Participants}

The study involved 700 adult male soccer players, age range from 18 to 35 , mean age $25.06 \pm 4.41$ years. They were divided into six age groups: 18 to 19 (U20) ( $\mathrm{n}=60) ; 20$ to 21 (U22) ( $\mathrm{n}=120) ; 22$ to 23 (U24) ( $\mathrm{n}=140) ; 24$ to 25 (U26) ( $\mathrm{n}=130) ; 26$ to 27 (U28) $(\mathrm{n}=130)$; and $28+$ years $(\mathrm{n}=120)$.

\section{Anthropometric procedure}

Body composition was assessed using the anthropometric measurement protocol by Matiegka (13). Besides the standing height and weight anthropometric parameters, limb circumferences (upper arm relaxed and flexed, forearm, thigh and calf), limb diameters (wrist, elbow, ankle and knee) and seven skinfolds (biceps, triceps, forearm, subscapular, thigh, calf and suprailiac) were also measured in this study. Participants' height was measured to the nearest $0.1 \mathrm{~cm}$ with a fixed stadiometer (Holtain Ltd., Crymich, U.K.), body weight to the nearest $0.1 \mathrm{~kg}$ using the SECA beam balance (Seca, Hamburg, Germany). Harpenden skinfold caliper (British indicators Ltd., Luton) was used to take skinfold thickness with $0.1 \mathrm{~mm}$ accuracy and the ankle diameter was measured using a Vernier caliper. Elastic tape was used to take circumferences with 0.01 accuracy. 
All measurements were performed on the right side of the body. Personal information of the participants (full name, date of birth, activity record) as well as anthropometric and ergometry test data were filled in a special software. Body mass components were calculated with a software formula based on Matiegka equation (13) and VO2max was calculated on the basis of Bruce norms. Body mass components are shown as relative, expressed as percentage of the whole body mass (relative muscle mass $\mathrm{MM} \%$, relative bone mass $\mathrm{BM} \%$ and relative fat mass $\mathrm{FM} \%$ or body fat percentage $\mathrm{BF} \%$ ). Absolute body mass components express how many kilograms of body mass accounts for muscular, bone or fat tissue (absolute muscular MMkg, absolute bone mass BMkg and absolute fat mass FMkg).

\section{Ergometry testing}

All participants underwent standard treadmill exercise testing according to the Bruce protocol which is a sub-maximal treadmill test, according to the ACSM guidelines (14). Bruce test consists of multiple stages of progressively increasing workloads, which should be performed until the examinee reaches his sub-maximal heart rate. The test includes 7 stages, each lasting for 3 minutes and with each subsequent stage the speed and the inclination of the track is significantly increased. VO2max is calculated from the Bruce nomogram using the exercise time (ET - duration of the test expressed in minutes) and the gender of the examinee.

\section{Statistical analysis}

Descriptive statistics including minimal, maximal and mean values, standard deviation and \pm 95 confidence interval were used for series with numerical attributes. Analysis of variance was used (F; p) for inferential statistics. The significance level was set at $\mathrm{p}<0.05$. The correlation between body mass components and ergometry results was examined by Pearson correlation coefficient ( $r$ ). Differences between age-different groups were assessed using one-way analysis of variance. Correction for multiple comparison was undertaken using Bonferroni method. Statistical analyses were performed using IBM SPSS v.20.0 statistical software (SPSS Inc., Chicago, IL, USA).

\section{RESULTS}

The basic anthropometric parameters and body mass components of all participants are presented in Table 1.

Anthropometric data for age-different adult soccer players and ANOVA results for inter-group differences are presented in Table 2.

All participants showed almost the same height, but body weight increased with the age, averagely $0.9 \mathrm{~kg}$ for every subsequent group. Relative muscle mass (MM\%) showed similar mean values across age different groups (ANOVA: $F=2.174$; $\mathrm{p}=0.06$ ) while absolute muscle mass (MMkg) showed tendency of increment with age, with significant difference between groups (ANOVA: $\mathrm{F}=2.136 ; \mathrm{p}=0.01)$. Body fat (BFkg and $\mathrm{BF} \%$ ) was statistically higher in the older groups (ANOVA $\mathrm{F}=3.737 ; \mathrm{p}<0.001 ;$ ANOVA $\mathrm{F}=4.117 ; \mathrm{p}<0.001)$ respectively.

Maximal oxygen consumption (VO2max) calculated from Bruce test and time of duration of the test (ET - exercise time) are presented in Table 3. The confidence interval (95\%) for VO2max for the whole sample was between 48.51 and $49.28 \mathrm{ml} / \mathrm{kg} / \mathrm{min}$. The best results were obtained by $\mathrm{U} 26$ group, but its result was statistically better only from the two older groups. Analysis of variance between groups was statistically significant for VO2max $(\mathrm{F}=4.82 ; \mathrm{p}=0.00)$ and for exercise times $(\mathrm{F}=4.87 ; \mathrm{p}=0.00)$. Post hoc Bonferroni multiple comparisons of maximal oxygen consumption among age-different groups showed statistically significant difference between two oldest groups (U28 and 28+) and two middle groups (U26 and U24), in favor of the younger athletes.

TABLE 1. Anthropometric data of the participants $(N=700)$

\begin{tabular}{lc}
\hline & Mean \pm SD \\
\hline Age (year) & $25.06 \pm 4.41$ \\
Height $(\mathrm{cm})$ & $178.32 \pm 6.14$ \\
Weight $(\mathrm{kg})$ & $74.0 \pm 7.64$ \\
MMkg & $40.29 \pm 4.67$ \\
MM\% & $52.75 \pm 2.63$ \\
BMkg & $12.59 \pm 1.46$ \\
BM\% & $16.63 \pm 1.29$ \\
BFkg & $11.13 \pm 2.8$ \\
BF\% & $14.12 \pm 1.54$ \\
\hline
\end{tabular}


TABLE 2. Descriptive statistics of anthropometric data for age different adult soccer players groups and comparison between the groups

\begin{tabular}{lcccccccc}
\hline & U20 $(\mathrm{n}=60)$ & $\mathrm{U} 22(\mathrm{n}=130)$ & $\mathrm{U} 24(\mathrm{n}=130)$ & $\mathrm{U} 26(\mathrm{n}=130)$ & $\mathrm{U} 28(\mathrm{n}=130)$ & $28+(\mathrm{n}=120)$ & \multicolumn{2}{c}{$\begin{array}{c}\text { ANOVA between } \\
\text { groups }\end{array}$} \\
\cline { 5 - 8 } & & & & & & & & $\mathrm{F}$ \\
\hline Age & $18.9 \pm 0.6$ & $21.15 \pm 0.5$ & $22.57 \pm 0.5$ & $24.51 \pm 0.5$ & $26.54 \pm 0.5$ & $31.45 \pm 2.7$ & & \\
Height $(\mathrm{cm})$ & $178.83 \pm 6.5$ & $178.25 \pm 5.69$ & $178.24 \pm 5.73$ & $177.72 \pm 5.96$ & $178.63 \pm 6.18$ & $178.49 \pm 5.7$ & 0.444 & 0.818 \\
Weight $(\mathrm{kg})$ & $73.9 \pm 7.8$ & $74.7 \pm 6.9$ & $75.9 \pm 8$ & $76.2 \pm 6.8$ & $77.2 \pm 7.2$ & $78.15 \pm 7.6$ & 4.247 & $0.001^{*}$ \\
MM\% & $53.27 \pm 1.79$ & $52.78 \pm 1.92$ & $52.21 \pm 3.01$ & $53.09 \pm 2.47$ & $52.69 \pm 3.4$ & $52.76 \pm 2.26$ & 3.292 & 0.06 \\
MMkg & $39.34 \pm 4.4$ & $39.51 \pm 4.43$ & $39.65 \pm 4.68$ & $40.44 \pm 4.15$ & $40.80 \pm 4.88^{*}$ & $41.30 \pm 5.01^{*}$ & 2.136 & $0.01^{*}$ \\
BM\% & $16.95 \pm 1.2$ & $16.84 \pm 1.29$ & $16.68 \pm 1.22$ & $16.49 \pm 1.36$ & $16.5 \pm 1.2$ & $16.51 \pm 1.39$ & 1.291 & 0.27 \\
BMkg & $12.41 \pm 1.5$ & $12.46 \pm 1.3$ & $12.56 \pm 1.36$ & $12.51 \pm 1.57$ & $12.67 \pm 1.34$ & $12.83 \pm 1.62$ & 2.174 & 0.06 \\
BF\% & $13.92 \pm 1.7$ & $13.79 \pm 1.41$ & $14.16 \pm 1.78$ & $13.87 \pm 1.31$ & $14.22 \pm 1.42^{*}$ & $14.29 \pm 1.54^{*}$ & 4.117 & $0.001^{*}$ \\
BFkg & $10.23 \pm 1.98$ & $10.29 \pm 1.75$ & $10.69 \pm 2.4$ & $10.49 \pm 1.66$ & $10.94 \pm 1.85^{*}$ & $11.13 \pm 2.08^{*}$ & 3.737 & $0.001^{*}$ \\
\hline
\end{tabular}

*Statistically significant difference

TABLE 3. Descriptive statistics of maximal oxygen consumption (VO2max) and exercise time (ET) for age different groups

\begin{tabular}{|c|c|c|c|c|c|c|c|}
\hline & \multirow[t]{2}{*}{ Mean } & \multirow[t]{2}{*}{ Std. deviation } & \multirow[t]{2}{*}{ Std. error } & \multicolumn{2}{|c|}{$95 \%$ confidence interval for mean } & \multirow[t]{2}{*}{ Minimum } & \multirow[t]{2}{*}{ Maximum } \\
\hline & & & & Lower bound & Upper bound & & \\
\hline \multicolumn{8}{|c|}{ VO2max $(\mathrm{ml} / \mathrm{min} / \mathrm{kg})$} \\
\hline U20 & 48.05 & 6.52 & 0.81 & 46.42 & 49.67 & 27.00 & 65.00 \\
\hline U22 & 48.90 & 4.11 & 0.40 & 48.10 & 49.69 & 36.00 & 60.00 \\
\hline U24 & 49.79 & 4.77 & 0.41 & 48.98 & 50.60 & 29.00 & 60.00 \\
\hline U26 & 50.24 & 4.80 & 0.41 & 49.42 & 51.06 & 34.00 & 70.00 \\
\hline U28 & 48.06 & 5.26 & 0.46 & 47.15 & 48.97 & 35.00 & 62.00 \\
\hline $28+$ & 47.89 & 5.47 & 0.46 & 46.97 & 48.81 & 30.00 & 64.00 \\
\hline Total & 48.89 & 5.17 & 0.19 & 48.51 & 49.28 & 27.00 & 70.00 \\
\hline \multicolumn{8}{|c|}{ ET (minutes) } \\
\hline U20 & 13.36 & 2.77 & 0.35 & 12.67 & 14.05 & 6.00 & 22.00 \\
\hline U22 & 13.77 & 1.80 & 0.18 & 13.42 & 14.12 & 9.00 & 19.00 \\
\hline U24 & 14.17 & 2.09 & 0.18 & 13.82 & 14.53 & 7.00 & 21.00 \\
\hline U26 & 14.40 & 2.14 & 0.18 & 14.04 & 14.77 & 8.00 & 23.00 \\
\hline U28 & 13.38 & 2.26 & 0.20 & 12.99 & 13.77 & 9.00 & 20.00 \\
\hline $28+$ & 13.45 & 2.37 & 0.20 & 13.06 & 13.85 & 7.00 & 20.00 \\
\hline Total & 13.79 & 2.25 & 0.08 & 13.63 & 13.96 & 6.00 & 23.00 \\
\hline
\end{tabular}

U26 group had significantly longer exercise time (ET $=14.40 \pm 2.14$ minutes) than the youngest (U20) and the oldest groups (U28, 28+).

The relationship between active and passive body mass components and ergometry results are shown in Table 4. Pearson coefficient was weak by intensity, but as we expected positive between the fitness indicator and muscle mass $(\mathrm{r}=0.218, \mathrm{p}=0.000)$ and negative with body fat percentage $(r=-0.182$, $\mathrm{p}=0.001)$.
TABLE 4. Results of correlation between Bruce test results and muscular mass and body fat percentage

\begin{tabular}{lcc}
\hline & MM\% & FM\% \\
\hline ET (minutes) & & \\
Pearson correlation & $0.182^{*}$ & $-0.117^{*}$ \\
Sig. (2-tailed) & 0.000 & 0.001 \\
VO2 max (m//kg/min) & & \\
Pearson correlation & $0.243^{*}$ & $-0.080^{*}$ \\
Sig. (2-tailed) & 0.000 & 0.034 \\
\hline
\end{tabular}

*Statistically significant $(p<0.005)$ 


\section{DISCUSSION}

The results of the present study describe the body composition and oxygen consumption in adult male soccer players in the Republic of Macedonia. To our knowledge there is no available data in the literature regarding body composition and maximal oxygen consumption estimated through Bruce protocol, which could be used as normative values for soccer players to aim to. There are normative values for VO2max for sedentary population, but not for athletes' population. Usually, the estimation of body composition and oxygen consumption in athletes is performed on individual level. Current results are compared to the earlier ones, and it is estimated is there a change (increment or decrement) in body composition and in physical fitness. Such comparison is practical for sport physicians and useful for coaches. Nevertheless, our intent was to obtain anthropometric and ergometry data for a larger group of soccer players in order to enable comparison of one soccer player to a large population of soccer players from our and from other countries.

The average muscle body component was $52.75 \%$ $(40.29 \pm 4.67 \mathrm{~kg})$ of the total body mass of the players from the whole sample. There was no significant difference in the relative muscle component (\%) among age different groups but there was a trend for gradual increment of the absolute muscle mass related to the age of the subjects. The players from the oldest group in whom the process of growth and constant development had been completed showed the highest values of absolute muscle mass $(41.29 \pm 5.01 \mathrm{~kg})$ compared to the youngest players $(\mathrm{U} 20=39.34 \pm 4.43 \mathrm{~kg})$, with statistical significance of $\mathrm{p}=0.01$.

Available data from literature show that muscle mass has rarely been analyzed as a body component. Most of the information is about adipose component, which has frequently been used as a parameter in different studies $(15,16)$. In soccer players, muscle mass has been analyzed from the functional aspect, with the use of motor tests and from anthropometric aspect as a component of lean body mass or as a fat free mass (FFM). Muscle body component is rarely analyzed. One of the few data available from literature origins from a study on a small group of young soccer players in Check Republic, who showed skeletal muscle mass $(39.30 \pm 3.35 \mathrm{~kg})$, almost identical with the one of our subjects in the same age group (39.34 $\pm 4.43 \mathrm{~kg})$ (17). Morphological components in players of five teams from the Serbian and Montenegro $1^{\text {st }}$ division suggest that the percent of muscle mass in these athletes was $51.23 \%$ (18).

The bone body component, analyzed as relative and absolute value was insignificantly different among the investigated groups. Although the relative bone mass (BM\%) was the highest in the youngest group and gradually decreased with age, the difference was insignificant, opposed to the absolute bone mass (BMkg) which showed mild insignificant increment within the age span (from the youngest to the oldest age group).

The adipose component is the most interesting of all body components for sport scientists. The values of the relative adipose component or body fat percentage $(\mathrm{BF} \%)$ were statistically different among groups, nevertheless they were not related to age. Within the whole sample, $\mathrm{BF} \%$ varies in the range from very low $10 \%$ to very high $21 \%$. Highest values were obtained in soccer players aged up to twenty four (U24=14.46 $\pm 1.78 \%$ ) while the lowest values were registered in soccer players aged up to twenty two $(\mathrm{U} 22=13.79 \pm 1.41 \%)$. The values of the absolute fat mass (FMkg) were the lowest in the youngest soccer players (U20 $=10.23 \pm 1.98 \mathrm{~kg})$ and the highest in the eldest players $(\mathrm{U} 28+=11.13 \pm 2.08 \mathrm{~kg})$.

The average fat percent in our participants was $14.12 \pm 1.54 \%$ and it was considerably higher than the values of fat percent reported in most other studies. According to our knowledge, the values of the body fat percentage (BF\%) calculated with the Matiegka formula, lower than 13\% are noted in individuals with very low amount of subcutaneous adipose tissue. Depending of the type of sport, optimal values of $\mathrm{BF} \%$, calculated according to Matiegka, in male athletes would be from $13.5 \%$ to $14.5 \%$. Almost sixty percent of the subjects in our sample $(59.7 \%, \mathrm{~N}=425)$ showed $\mathrm{BF} \%$ from $13 \%$ to $14 \%$. Seven percent $(\mathrm{N}=53)$ of the athletes showed lower values of BF\% (12\%), while only five subjects $(0.6 \%)$ showed extremely low values of $\mathrm{BF} \%=10 \%$. Intolerably high percentage of adipose tissue of $\mathrm{BF} \%=17-21 \%$, was registered in seven percent of the subjects $(\mathrm{N}=50)$. 
A number of studies performed on full time soccer players both at club and international level report on the percentage of body fat within the range of 9.8 to $10.7 \%$ (19-21). Investigations in Brazilian soccer population found values around 11.19 BF\% $(22,23)$ and Santos showed mean values of $11.1 \pm 1.3$ and $11.4 \pm 2.6 \mathrm{BF} \%$ (24). The study which investigated body mass components in elite soccer players in United Arab Emirates, using measurements of skinfolds and Siri equation, found body fat percent of $11.6 \pm 2.1 \%$. In the same study VO2max was $62.3 \pm 5.1 \mathrm{ml} / \mathrm{kg} / \mathrm{min}$, estimated by incremental treadmill test (25). Serbian non-elite soccer players are higher $(180.8 \pm 7.1 \mathrm{~cm}$ vs $178.32 \pm 6.14 \mathrm{~cm})$ but lighter $(74.4 \pm 6.9 \mathrm{~kg}$ vs $76.31 \pm 7.64 \mathrm{~kg})$ than Macedonian soccer players, and they have lower body fat percentage (according to Jackson - Pollock equation, fat content $\%=10.8 \pm 2.1$ vs Matiegka equation in our study, BF\% 14.12 \pm 1.54 ) (26). Nikoladis used anthropometric measurements of 10 skinfold and calculated body fat percentage with the formula by Porizkova in adult Greek soccer players, $(21.7 \pm 3.4$ years $)$ was $15.9 \pm 3.5 \%$ (27).

Maximal oxygen consumption across age-different groups in our sample of adult soccer players showed the highest values in U26 $\left(50.24 \pm 4.80 \mathrm{mlkg}-{ }^{1} \mathrm{~min}-{ }^{1}\right)$, but they were significantly higher only from the U28 and 28+ groups. There were no significant differences between other groups. ANOVA test showed presence of age groups differences $(\mathrm{F}=4.82$, $\mathrm{p}<0.005)$ but multiple comparisons showed that statistical significance was limited only on U26 and two oldest groups. This statistics shows homogeneity in VO2 max values in players who played in national soccer club division.

The average VO2max for the whole sample was $48.9 \pm 5.17 \mathrm{ml} \mathrm{kg-}{ }^{1} \mathrm{~min}^{-1}$. The lowest value of VO2max was $27 \mathrm{ml} / \mathrm{kg} / \mathrm{min}$, while the highest value was $70 \mathrm{ml} / \mathrm{kg} / \mathrm{min}$. The confidence interval (95\%) for VO2max for total groups was between 48.51 and $49.28 \mathrm{ml} / \mathrm{kg} / \mathrm{min}$. This result differs from the reported ones for elite soccer players in the literature. It is even below the lower limit of the estimated VO2max values range of 55 to $70 \mathrm{mlkg}-1 \mathrm{~min}-1$ (28). According to a study which investigated the maximal aerobic power features of male professional soccer players from 1989 to 2012 year in Norway, VO2max values of 62 to $64 \mathrm{ml} / \mathrm{kg} / \mathrm{min}$ fulfill the demands for aerobic capacity in men's professional soccer players (29). In his review paper Hoff reported that the average oxygen uptake for international soccer teams ranges from 55 to $68 \mathrm{ml} / \mathrm{kg} / \mathrm{min}$ (30). In the review of maximal oxygen uptake in young soccer players in Brazil, U20 players showed the highest maximal oxygen uptake of $56.58 \pm 5.03 \mathrm{ml} / \mathrm{kg} / \mathrm{min}$. It was estimated as lower than the ones reported for the same category of players from other countries. This may be a reflection of the style of play used in Brazilian soccer (31). Research in Serbian elite and non-elite soccer players reported mean values of $\mathrm{VO} 2$ max of $53.5 \pm 8.6$ and $42.9 \pm 6.6 \mathrm{ml} \mathrm{kg}^{-1} \mathrm{~min}^{-1}$ respectively (26). Improvement in the maximal oxygen consumption from $48.0 \pm 2.5$ to $56.8 \pm 4.3 \mathrm{mlkg}^{-1} \mathrm{~min}^{-1}$ after 6 week specific endurance training regime was reported in a paper which investigated the aerobic capacity in Serbian professional soccer players (32). Functional characteristics of elite soccer players in Serbian and Montenegro soccer division, showed average values of VO2max from 42.40 to $54.45 \mathrm{mlkg}^{-1} \mathrm{~min}^{-1}$ regarding the players position, whereas the lowest values were in goalkeepers opposed to the highest ones in midfield players (18).

It should be noted that most of the studies presented in this discussion obtained data for maximal oxygen consumption from direct and maximal methods. Results found in the present study were estimated by submaximal and indirect method, which may be the reason for lower VO2max values in Macedonian soccer players.

The size of muscle and adipose component is important because these body components could be used for the evaluation of the effectiveness of a certain nutritive and training regime. Their quantification is also most necessary because the maintenance of the muscle and adipose component on optimal level has positive effects on physical fitness. The correlation between VO2max and $\mathrm{MM} \%$ in our study was weak and positive $(\mathrm{r}=0.243 ; \mathrm{p}=0001)$. There was a weak negative correlation between relative adipose component and VO2max, $r=-0.18 ; \mathrm{p}=0.03)$. Weak positive correlation was estimated between the duration of Bruce test and the muscle mass ( $r=0.182 ; \mathrm{p}=0.01)$, while there was a weak negative correlation with the adipose component $(\mathrm{r}=-0.117 ; \mathrm{p}=0.04)$. These results are in accordance with the hypothesis that 
subjects with a larger muscle mass show greater endurance and higher oxygen consumption, while the subjects with larger adipose component show shorter duration of the Bruce test with lower VO2max. Ostojic and Zivanic reported that in elite Serbian soccer players the main improvements in the sprint time were associated with the reduction in body fat percentage. They found a negative correlation between body fat percentage and physical performance, as body fat content decreased during the season while players became faster (1). Strong negative correlation between body fat and predicted VO2max $(r=-0.65)$ was found in American national men soccer players. Collegiate soccer players $(B F \%=13.9 \pm 5.8)$ also show weak to moderate correlations between body composition and physical performance (33).

There are few studies that have shown no relationship between body composition, except for body mass and physical performance (34). The relationship between body composition and performance remains unclear, especially in highly trained athletes. Some of the reasons for that could be the usage of different methods for the estimation of body fat percentage, different times of data collection, and differences in training programs. Therefore, multicenter studies which employ unified protocols and methods of estimation should be performed with an aim to obtain data from different settings and to enable comparison of these data.

The value of adipose body component in our soccer players is higher, while $\mathrm{VO} 2 \mathrm{max}$ is lower compared to studies performed on professional soccer players in developed countries, which have achieved much better results in national leagues and in international encounters. Our results regarding both parameters are similar to the data obtained from the Serbian, Croat and Greek soccer players $(1,3,18,26,32)$. It seems that, along with the tactics of the game, motor skills and psychological factors, which undoubtedly influence the athletes' performance, it is most necessary that better physical training and nutritional regime than the current in our soccer players should be developed and established during the period of preparation and during the season in order to achieve better football results.

\section{CONCLUSION}

The total body mass in age-different soccer players in our country showed that although they were with the same height, their body weight significantly increased with age. Despite the wide age span of adult soccer players in our study, they showed homogeneity regarding muscle and bone mass body components. The body fat component was slightly higher in the two oldest groups. Soccer players in the Republic of Macedonia show similar body fat percent and VO2max to soccer players from neighboring countries and worse values of both parameters than players from countries with high football ranking. Our results confirm the assumption that subjects with larger muscle mass have greater endurance and higher maximal oxygen consumption compared to subjects with larger body fat component. Strategies for decrement of body fat in our adult soccer players are necessary to be developed and established on every level of athletes' preparation and during season in order to achieve better performance and better physical fitness and endurance.

\section{CONFLICT OF INTEREST}

The authors declare no conflict of interest.

\section{REFERENCES}

1. Ostojic SM, Zivanic S. Effects of training on anthropometric and physiological characteristics of elite Serbian soccer players. Acta Biol Med Exp 2001; 27: 76 .

2. Rico-Sanz J. Body composition and nutritional assessments in soccer. Int J Sport Nutr 1998; 8: 113-123.

3. Popovic S, Akpinar S, Jaksic D, Matic R, Bjelica D. Comparative study of anthropometric measurement and body composition between elite soccer and basketball players. Int J Morpol 2013; 31(2):461-467. http://dx.doi.org/10.4067/S0717-95022013000200016.

4. Wilmore J, Haskell W. Body composition and endurance capacity of professional football players. J Appl Physiol 1972;33:564-7.

5. Howley ET, Basset DR, Welch HG. Criteria for maximal oxygen uptake: review and commentary. Med Sci Sport and Exerc 1995;27: 1292-01. http://dx.doi.org/10.1249/00005768-199509000-00009.

6. Kalapotharakos V, Ziogas G, Tokmakidis SP. Seasonal aerobic performance variations in elite soccer players. J Strenght Cond Res 2011; 25(6):1502-7. http://dx.doi.org/10.1519/JSC.0b013e3181da85a9.

7. Hoff J, Helgerud J. Endurance and strength training for soccer players, Physiological considerations. Sports Med 2004; 34(3): 165-80. http://dx.doi.org/10.2165/00007256-200434030-00003.

8. Silvestre R, Kraemer WJ, West C, Judelson DA, Spiering BA, Vingren JL, Hatfield DL, Anderson JM, Maresh CM. Body composition and physical performance during a national collegiate athletic association division I men's soccer season. J Strength \& Conditioning Research 2006;20(4):962-70. http://dx.doi.org/10.1519/r-18165.1. 
9. McIntyre MC. A comparison of the physiological profiles of elite Gaelic footballers, hurlers and soccer players. Br J Sports Med 2005;39:437-439. http://dx.doi.org/10.1136/bjsm.2004.013631.

10. Pigozzi F, Glombini A, Fagnani F, Di Salvo V. Evaluation of Whole Physical Condition. http://eknygos.Ismuni.It/springer/160/33-41.pdf.

11. Pluncevic Gligoroska J, Todorovska L, Dejanova B, Maleska V, Mancevska S, Nikolic S. Anthropometric Parameters in National Footballers in the Republic of Macedonia. Contributions, Sec.Med.Sci 2013;35(2):147-54.

12. Nikolic S, Todorovska L, Maleska V, Dejanova B, Efremova Lj, Zivkovic V, Pluncevic Gligoroska J. Analysis of Body Mass Components in national club football players in Republic of Macedonia. Med Arh 2014; 68(3):191-194. http://dx.doi.org/10.5455/medarh.2014.68.191-194.

13. CattrysseE,ZinzenE,CaboorD,DuquetP,VanroyP,ClaryssJ.Anthropometric fractionation of body mass: Matiegka revisited. J Sport Sciences 2002; 20: 717-723. http://dx.doi.org/10.1080/026404102320219428.

14. Bruce RA. Exercise testing of patients with coronary heart disease: principles and normal standards for evaluation. Ann Clin Res 1971; 3:323-332.

15. Hopkins W G, Anderson M E, Lee $H$. et al The LMI: a new practical index of lean mass for monitoring athletes [abstract]. Med Sci Sports Exerc 200234S237.

16. Duthie GM, Pyne DB, Hopkins WG, Livingstone S, Hooper SL. Anthropometry profiles of elite rugby players: quantifying changes in lean mass. Br J Sports Med 2006; 40(3): 202-7. http://dx.doi.org/10.1136/bjsm.2005.019695.

17. Botek Z, Gaba A, Lehnert M, et al. Condition and body constitution of soccer players in category $\mathrm{U} 19$ before and after completing a preparatory period. Acta Univ Palcki Olomuc Gymn 2010;40:47.

18. Berjan B, Suzovic D. Morfological components and functional characteristics of elite soccer players according to team position. http://www.smas.org/2-kongres/papers/5281.pdf.

19. Withers R, Craig N, Bourdan P, et al. Relative body fat and anthropometric prediction of body density of male athletes. Eur J Appl Physiol 1987;56:191-200. http://dx.doi.org/10.1007/BF00640643.

20. De Rose E. Determination of the ideal body weight and body composition of professional soccer players. In: Question of athletes nutrition: abstracts of the reports the International Symposium. Leningrad: Leningrad Institute of Physical Culture, 1975.

21. Raven $P$, Gettmen $L$, Pollock $M$, et al. A physiological evaluation of professional soccer players. $\mathrm{Br} \mathrm{J}$ Sports Med 1978;10:209-16. http://dx.doi.org/10.1136/bjsm.10.4.209.
22. Silva JF, Guglielmo LGA, Dittrich N, Floriano LT, Arins FB. Relação entre aptidão aeróbia e capacidade de sprints repetidos no futebol: efeito do protocolo. Rev Bras Cineantropom Desempenho Hum 2011;13:111-6.

23. Prado WL, Botero JP, Guerra RLF, Rodrigues CL, Cuvello LC, Dâmaso AR. Perfil antropométrico e ingestão de macronutrientes em atletas profissionais brasileiros de futebol, de acordo com suas posições. Rev Bras Med Esporte 2006;12:61-5. http://dx.doi.org/10.1590/S1517-86922006000200001.

24. Santos JAR. Estudo comparativo, fisiológico, antropométrico e motor entre futebolistas de diferente nível competitivo. Rev Paul Educ Fís 1999;13:146-9.

25. Magalhaes Sales M, Vieira Browne RA, Yukio Asano R, dos Reis Vieira Olher R, Vila Nova JF, Moraes, Simoes HG. Physical fitness and anthropometric characteristics in professional soccer players of the United Arab Emirates. Rev Andal Med Deporte 2014;7(3):106-10. http://dx.doi.org/10.1016/S1888-7546(14)70071-1.

26. Ostojic SM. Physical and physiological characteristic of elite Serbian soccer players. Facta Universitatis 2000;7 (1):23-29.

27. Nikoladis P. Age-related Differences in Countermovement vertical Jump in Soccer Players 8-31 years old: The role of Fat free mass. American Journal of Sports Science and Medicine 2014;2 (2):60-4. http://dx.doi.org/10.12691/ajssm-2-2-1.

28. Chin M, Lo Y, Li C, et al. Physiological profiles of Hong Kong elite soccer players. Br J Sports Med 1992;26:262-6.

29. Tonnessen E, Hem E, Leirstein S, Hauqen T, Seiler S. Maximal aerobic power characteristics of male professional soccer players, 1989-2012. Int J Sports Physiol Perform 2013; 8 (3):323-9.

30. HoffJ. Training and testing physical capacities for elite soccer players. JSports Sci 2005;23 (6):573-82. http://dx.doi.org/10.1080/02640410400021252

31. Da Silva CD, Bloomfield J, Marins JC. A review of stature, body mass and maximal oxygen uptake profiles of $\mathrm{u} 17, \mathrm{u} 20$ and first division players in Brazilian soccer. J Sports Sci Med 2008; 7 (3):309-319.

32. Ostojic SM, Stojanovic M, Jukic I, Pasalic E, Jourkesh M. The effects of six weeks of training on physical fitness and performance in teenage and mature top-level soccer players. Biol of Sport, 2009; 26(4):379-87. http://dx.doi.org/10.5604/20831862.901141

33. Silvestere R, West $\mathrm{C}$, Maresh $\mathrm{CM}$, et al. Body composition and physical performance in mens soccer: a study of national Collegiate Athletic Assosiation Division I team. J Strength Cond Res 2006;20:177-183.

34. Stempfle KJ, Katch FI, Petric DE. Body composition relates poorly to performance tests in NCAA division football players. J Strength Cond Res 2003; $17: 238-244$ 